\title{
A Geografia Política e suas múltiplas abordagens - o sistema territorial e uma precisão teórico-conceitual das fronteiras
}

\author{
The Political Geography and its multiple approaches - the territorial system and a theoretical
} and conceptual precision border

\section{Israel Monteiro Gonçalves \\ Rita de Cássia Liberato}

Pontifica Universidade Católica de Minas Gerais - PUC - Belo Horizonte - Minas Gerais - Brasil

\begin{abstract}
$\longrightarrow$
Resumo: Partindo do pressuposto que a Geografia Política requer uma ampliação no que se refere à suas múltiplas possibilidades de conexão escalar, é que se propõe o estudo em que se prioriza a complexidade de suas abordagens, sem negligenciar a sua carga histórica no que se refere às Geopolíticas estatais. O território como categoria de análise Geográfica é imprescindível para o estudo tendo em vista que é o lócus onde se concretiza as relações de poder. E, por fim, já que se aborda o conceito de território, se torna imperioso estabelecer no diálogo uma breve aproximação conceitual entre fronteira, limite e divisa.
\end{abstract}

Palavras-chave: Geografia Política. Território. Fronteira.

Abstract: Assuming that the Political Geography requires an extension with regard to its many connection possibilities climb, do you propose the study which prioritizes the complexity of their approaches, without neglecting its historical burden with regard to the Geopolitical State. Geographic Territory as a category of analysis is essential for the study given that is the locus where is realized the power relations. And finally, since it addresses the concept of territory, it becomes imperative to establish in a brief conceptual approach dialogue between border, boundary, and currency.

Keywords: Political Geography. Territory. Border. 


\section{A geografia política: possibilidades e conexões escolares}

Para a efetivação de estudos e análises no campo da Geografia Política é indispensável recorrer a seus clássicos. A partir desses será possibilitado realizar conexões dessa disciplina da Geografia, em várias escalas: local, regional, nacional e internacional.

De acordo com Lacoste. (1988, p. 216)

O raciocínio no âmbito mundial se torna, sem dúvida, cada vez mais indispensável, mas para ser eficiente, ele deve ser combinado com a observação em outros níveis da análise espacial. Os fenômenos de "planetarização" não fazem desaparecer, o que quer que possam dizer alguns, aquilo que se passa em níveis local, regional e nacional.

Este autor, ao comentar os argumentos amplamente utilizados pela Geografia Política, mais especificamente a francesa, que, prioritariamente, não apresenta o(s) fenômeno(s) com sua espacialidade, é enfático ao afirmar que essa não pode ser desconsiderada na compreensão e análise dos fenômenos políticos. Nas palavras do autor:

Esse argumento, que geralmente deriva de regras não ditas, mas não menos poderosas, da corporação, não é sério, na medida em que um bom número de fenômenos políticos essenciais são, eminentemente, espaciais e cartografáveis, tais como o Estado, suas fronteiras, suas subdivisões territoriais e sua estrutura urbana. (LACOSTE, 1988, p. 217).

Ainda de acordo com o autor, os estudos efetivados no campo da Geografia devem considerar as dimensões físicas e humanas que propiciam a ocorrência de determinado fenômeno desde que essas possam ser cartografáveis, ou seja, espaciliazadas na superfície do globo. Desse modo, a Geografia privilegia as configurações espaciais particulares de todas as espécies de fenômenos. Nesta perspectiva Lacoste (1988, p. 217) acrescenta:

"não se pode encontrar justificativa teórica para a exclusão, do campo da geograficidade, da categoria de fenômenos políticos que são cartografáveis (sobretudo dos relacionados as fronteiras) e cuja importância social é, quer queira, quer não, também indiscutível".

Neste contexto chama-se a atenção, como o faz o autor, para o fato da Geografia não poder desconsiderar a sua importância política e, muito menos, a relevância da política para os estudos geográficos. Continuando a sua análise sobre a atuação do geógrafo Lacoste (1988, p. 216) afirma: "Mas para isso é preciso formar geógrafos eficientes que tenham gosto e o senso da ação. É preciso também que eles estejam conscientes do procedimento, da importância dos fenômenos que advém do político." Assim, as contribuições desse autor são imprescindíveis para a formação de geógrafos e, também, para a efetivação de estudos principalmente em Geografia Política, pois não se pode negar que as ações humanas, em todos os âmbitos, são essencialmente políticas e, portanto, de poder.

O poder é parte intrínseca de toda relação, seja no nível econômico, social, político, cultural, administrativo, religioso, espacial, etc.. Desta forma, se situa em todos os lugares, mesmo que não seja percebido de modo claro pelos atores sociais reais e concretos. Como esses ocupam áreas e a ocupação dessas não se dá homogeneamente tem-se aqui um foco de conflito, pois a própria apropriação desigual do espaço entre os indivíduos/grupos sociais é inegavelmente fonte de tensão e, por extensão, de conflito. Desse modo, o poder está vinculado permanentemente à Geografia Política. De acordo com a literatura sobre o tema, o poder se concretiza nas mais variadas formas e em todas as relações vivenciadas nas sociedades capitalistas que tem a competição como processo social mais explícito (HORTON e HORTON, 1975).

Buscando definir o poder, Foucault (1979) faz uma série de proposições. A partir dessas, além de esclarecer a natureza do poder, o apresenta como um fenômeno multidimensional. Para este autor, a intencionalidade do ato é reveladora da importância das finalidades que os caracteriza, pois o poder visa o controle e a dominação dos homens por outros 
homens e desses sobre as coisas. (Foucault, 1979). Nesse sentido, Arendt (1985, p. 24) citada por Souza (1995, p. 80) afirma:

O poder jamais é propriedade de um indivíduo; pertence ele a um grupo e existe apenas enquanto o grupo se mantiver unido. No momento em que o grupo, de onde se originaram o poder, desaparece, o seu poder também desaparece. (...) Sem um povo ou um grupo não há poder.

Nessa esfera insere-se a Geografia Política que possibilita efetivar análises em diferentes escalas, desde a tradicional, que tem como seu objeto a Nação (Estado Nacional), ou seja, população, território e seus recursos. A população, nesta perspectiva, vem em primeiro lugar, porque está, segundo seus defensores, na origem de todo poder, pois consideram que nela reside a capacidade de transformação. O território, como categoria de análise geográfica, é, também para esses, indispensável porque é o lócus onde se concretiza o poder e objeto de disputa entre as nações. Por fim, tem-se os recursos, que são, via de regra, o motivo pelo qual ocorre disputa por determinada área. Lacoste (1988, p. 131) declara: "É cada vez mais necessário que os geógrafos se preocupem com os problemas políticos e militares e reencontrem, assim, aquilo que foi, durante séculos, uma das razões de ser fundamentais do seu saber." Becker (1995, p. 271) ressalta que na atualidade há uma retomada de interesse pela Geopolítica. De acordo com a autora:

A retomada de interesse pela Geopolítica é patente. Grupos de trabalho, livros, artigos sucedem relevando a revalorização das relações entre poder, ou mais precisamente a prática do poder, e o espaço geográfico, relação que constitui a preocupação central da disciplina.

Importante colocar também as palavras de Lacoste (1988) no que se refere a importância da Geografia Política que representa umas das razões do saber do Geógrafo.

(...) estabelecidas em escalas diferentes, permitam agir a superposição dos problemas e das relações de forças em função de territórios de extensão maior, ou menor.
Nesse domínio, o saber pensar o espaço dos geógrafos aparece com toda a sua eficácia. Não se trata evidentemente de reduzir a Geografia ao raciocínio Geopolítico, mas este foi durante tanto tempo excluído das preocupações dos geógrafos, e tão poucos se preocupam ainda hoje com ele, que é preciso destacar sua importância e seu interesse (LACOSTE, 1988, p.220).

Neste contexto Horta (2006) aponta algumas questões que são frequentemente colocadas, principalmente no meio acadêmico com o objetivo de elucidar os termos em que se dá o debate e a real importância/significância do mesmo. Dentre as questões colocadas pelo autor, salientamos a pertinência para este trabalho da problemática levantada sobre a redução da Geografia Política e da Geopolítica apenas a escala dos Estados Nacionais. Para Horta (2006), como consequência, ocorre uma descontextualização conceitual que, por sua vez, restringe o olhar de muitos pesquisadores diante das relações que envolvem território e política.

(...) as relações entre espaço e poder transcendem a ação dos Estados, porém, os trabalhos de geografia política e geopolítica, de um modo geral, não vêm acompanhando, satisfatoriamente, os mais recentes movimentos politicamente organizados que atuam contra e/ou independentemente do Estado. (HORTA, 2006, p.51).

Para Horta (2006) a Geografia Política é a consciência geográfica do território, provocando a colocação original de Haushofer que defendia que a Geografia Política deveria ser a "consciência geográfica do Estado", prevalecendo uma concepção, segundo o autor, equivocada de que essa disciplina da Geografia forma um conjunto de conhecimentos vinculados, tão somente, ao poder e a ação dos Estados Nacionais. Ainda segundo o autor, essa visão restritiva do campo de ação da Geopolítica e da Geografia Política tem, provavelmente, relação com o contexto de formação e/ou expansão dos Estados Nacionais. Segundo Costa (1992), citado por Horta (2006):

(...) o surgimento da geografia política e, sobretudo, da geopolítica são um produto do contexto europeu (...) com Ratzel e R. Kjélen (...) 0 interesse pelos fatos referentes à 
relação entre espaço e poder, também manifestava um momento histórico (...) caracterizado pela emergência das potências mundiais (...). (COSTA, 1992, p.58-59)

Porém, não se trata de um objeto restrito, ressalta ainda, Costa (1992) apud Horta (2006). Pois os estudos que envolvem o Estado, a sociedade e o território, por exemplo, são demasiadamente complexos. O que se questiona é a "exclusividade" do Estado diante de outras formas de poder institucional e territorial. Para Raffestin (1993) essa restrição, ainda persistente, pode ter correlação com a produção original de Ratzel: "Para Ratzel, tudo se desenvolve como se o Estado fosse o único núcleo de poder (...) a geografia política de Ratzel é uma geografia do Estado". (Visentini, 1987, p.32, apud Horta, 2006, p.62).

Claval (1979) citado por Horta (2006) em sua análise sobre o papel da Geografia Política e da Geopolítica apresenta que a visão tradicional dessa área da Ciência Geográfica negligenciou, devido ao fato de se restringir aos estudos/análises de fenômenos na escala dos Estados Nacionais, as relações de poder exercidas no interior dos Estados Nacionais. De acordo com o autor:

as dimensões espaciais dos fatos de poder foram negligenciadas. A geografia política voltou-se prematuramente para a análise do Estado e não soube dissecar as engrenagens dos governos e sua articulação sobre a sociedade civil. O problema do poder é, em primeiro lugar, o da transmissão do fluxo de informações, o acesso a ideias novas, o controle da terra, o controle da mão-de-obra e etc. (CLAVAL, 1979, p. 215)

Para Becker (1995, p.303), citada por Horta (2006, p.61), “(...) o Estado certamente não é a unidade única representativa do político nem o território nacional a única escala do poder." Nesse sentido, pode-se afirmar que a Geografia Política não está restrita as ações do Estado Nacional, podendo, ser aplicada para estudar, compreender, analisar e explicar relações políticas em outras escalas territoriais, especialmente nas microescalas onde indivíduos e/ou grupos sociais atuam de modo decisivo em suas vidas reais e concretas. Conforme aponta Horta (2006),

(...) vale reforçar que o foco territorial deve também, extrapolar a escala nacional. Desta forma, temas que tratem, por exemplo, das relações de poder num minifúndio, em um pequeno município brasileiro, numa micro bacia hidrográfica, etc., merecem ser estudados (...) outras instâncias do poder, outras territorialidades e diferentes formas de gestão da sociedade - e que em muitos casos estão, inclusive, conectados aos aparelhos de Estado - constituem "objetos" de investigação que podem ser abordados em geopolítica ou em geografia política. (p. 62-63).

Ainda de acordo com Becker (1995, p.274) "Centrar o foco no Estado-nação é tratá-lo como unidade exclusiva de poder e assumir que os conflitos se dão apenas entre Estados”. Chama-se a atenção para o fato de, além de reduzir as possibilidades de análise, a relação espaço-poder, muitas vezes, transcende o Estado.

A geógrafa Berta Becker ainda ressalta que as novas territorialidades desenvolvem-se acima e abaixo da escala do Estado e desafiam os fundamentos do poder nacional e a possibilidade de desenvolvimento. Nesse contexto, Horta (2006) também aponta que as pesquisas em geografia política destinadas a tratar dos Estados nacionais permanecem muito relevantes, ainda mais quando consideradas as transformações atuais em sua conformação política e territorial. Porém, em razões dessas mudanças que outras organizações de poder e outras territorialidades devem compor, com maior vigor, objetos de interpretação em Geografia Política e Geopolítica.

De acordo com esse autor, a Geografia Política configura para muito além dos Estados nacionais. Horta (2006) ainda salienta que, delegar estratégias de organização política do espaço somente aos Estados significa, de fato, reduzir as relações entre o espaço geográfico e a política a um determinado contexto histórico geográfico. Segundo ele, há um vasto campo de análise que supera as pesquisas destinadas às "geopolíticas estatais". Nesse sentido apresenta algumas das inúmeras possibilidades de estudos/análises em Geografia Política e Geopolítica 
sobre outros fenômenos que envolvem relações de poder e espaço. Ressalta-se que essas análises, de acordo com Horta (2006), devem ter na interdisciplinaridade a sua base teórico-conceitual.

\begin{abstract}
(...) outras conexões poderiam ser realizadas mais solidamente: a geografia urbana com a geografia política, essa última com a geografia agrária, etc. Geopolíticas que se manifestam predominantemente em escala local permitem a análise, por exemplo, da organização política de um assentamento rural (...) articulações que não se limitam às ramificações da Geografia, pois a geografia urbana, por exemplo, "comunica-se" com a sociologia urbana, com a antropologia, com o urbanismo e etc.; portanto são inúmeras as possibilidades de conexões da geopolítica ou da geografia política com áreas e sub-áreas do conhecimento acadêmico. (HORTA, 2006, p.64-65).
\end{abstract}

Portanto, outras organizações de poder e outras territorialidades, independentemente de suas variações e conexões escalares, acima e/ou abaixo da escala dos Estados Nacionais merecem e podem ser efetivadas no âmbito dos trabalhos em Geografia Política e Geopolítica. Ainda no sentido de demonstrar o quanto os estudos/análises em Geografia Política e Geopolítica podem ser ampliados, a seguir, trataremos de um conceito chave no âmbito dessas, ou seja, o território.

\section{0 território na geografia política}

A palavra território faz pensar o Estado, pois evoca o território nacional, porém, o território não deve ser reduzido a essa escala ou associado apenas com a figura do Estado. Assim como a Geografia Política, o território trás, historicamente, consigo uma carga ideológica na literatura científica da área, pois nessa é concebido tão somente como território nacional. Caminhando no sentido mais amplo dessa categoria geográfica e palavra chave da Geografia Política, através da literatura a partir da década de 1970 em diante, amplia-se a visão do conceito de território nas mais variadas dimensões. Nas palavras de Souza (1995, p.81), os territórios existem e são construídos e descontruídos nas mais diversas escalas, da mais acanhada (uma rua, por exemplo) à internacional. Territórios podem ter um caráter permanente, mas também podem ter uma existência periódica, cíclica.

O território surge na Geografia Política como espaço concreto em si, tanto com atributos naturais como os socialmente construídos. A ocupação de determinado espaço gera raízes e identidade, provocando a ideia de que quem (indivíduo/grupo) se apropria de um espaço, impõe a sua identidade sócioeconômica e cultural ao espaço concreto. Nesse sentido Souza aponta que:

(...) os limites do território não seriam, a bem da verdade, imutáveis (...) fronteiras podem ser alteradas comumente pela força bruta mais cada espaço seria, enquanto território, território durante todo o tempo, pois apenas a durabilidade poderia, é claro, ser geradora de identidade sócio-espacial, identidade na verdade não apenas com o espaço físico, concreto, mas com o território e, por tabela, com o poder controlador desse território. (SOUZA, 1995, p.84)

O território é, por excelência, um espaço político, o campo de ação dos sujeitos sociais. Devese ter claro que espaço e território não são conceitos equivalentes e para a distinção dos mesmos torna-se essencial defini-los indicando as suas características fundamentais, suas possibilidades e limites teóricoconceituais. Uma das distinções importantes a se salientar é citada por Raffestin (1993), trazendo a ideia de que o espaço está mais próximo de uma "noção" e o território de um "conceito". Ainda segundo Raffestin, citado por Haesbaert (2010), espaço e território não se equivalem, sendo o espaço antecedente ao território. Nesse sentido tem-se que o território resulta de "uma ação conduzida por um ator sintagmático (que realiza um programa) em qualquer nível." (RAFFESTIN, 1993, p.143), não sendo, portanto, somente no nível do Estatal Nacional.

Importante colocar que o espaço, conforme Soja (1971) e Clark (1985), é uma arena onde as classes sociais travam suas lutas cotidianas. Também é o lócus dos embates entre os detentores de poder, em especial, entre estados-nações e, no âmbito desses, entre os seus membros (estados, provinciais, municípios e grupos sociais de interesses variados). 
Deve ser ressaltado que mesmo no interior de um município ocorre conflito territorial entre agrupamentos humanos que se apropriam de espaços, impedindo que outros (não pertencentes ao grupo) partilhem esses espaços. Neste sentido o território se forma a partir do espaço e no espaço, sendo o resultado de ações conduzidas por atores sociais em diversos níveis. Ao se apropriar de um espaço concreta ou abstratamente, 0 ator "territorializa" o espaço (RAFFESTIN, 1980, p.143).Todo espaço definido e delimitado por e a partir das relações de poder, é um território, do quarteirão aterrorizado por uma gangue de jovens até o bloco constituído pelos países membros da OTAN. (SOUZA, 1995, p. 111).

Nesse sentido, não cabe procurar a distinção evidente e clara entre espaço e território, sendo que o território não existe sem 0 espaço. Embora demonstrado pelos autores que eles não se equivalem. Haesbaert (2010, p.166), afirma que

ao território cabe a focalização na espacialidade das relações de poder. O território se define mais estritamente a partir de uma abordagem sobre o espaço que prioriza ou que coloca seu foco, no interior dessa dimensão espacial, (...) nas problemáticas de caráter político ou que envolvem a manifestação/realização das relações de poder, em suas múltiplas esferas.

Continuando sua análise sobre território, Haesbaert (2004, p.79) acrescenta: “(..) o território pode ser concebido a partir da imbricação de múltiplas relações de poder, do poder mais material das relações econômico-políticas ao poder mais simbólico das relações de ordem mais estritamente cultural.

Lefebvre (1978, p. 259) afirma que " $A$ produção de um espaço, o território [...], espaço físico, balizado, modificado, transformado pelas redes, circuitos e fluxos que aí se instalam: rodovias, canais, estradas de ferro, circuitos comerciais e bancários, auto-estradas e rotas aéreas, etc." (1978, p. 259) O território nessa perspectiva, é um espaço onde se projeta um trabalho, seja ele energia e/ou informação, e que, por consequência, revela relações marcadas pelo poder. "O espaço é a 'prisão original', o território é a prisão que os homens constroem para si”. (RAFFESTIN, 1980, p. 144)

No sistema territorial, os indivíduos e/ou grupos ocupam pontos do espaço e se distribuem de acordo com os modelos que podem ser aleatórios, regulares ou concentrados. Segundo Raffestin (1980), na análise dos territórios deve-se ter em conta que esses são, em grande parte, respostas possíveis a dois fatores fundamentais para os seres humanos, ou seja, à distância e à acessibilidade.

Com relação à distância é importante apontar que esta pode ser apreendida em termos espaciais (distância física ou geográfica), temporais, econômicas, sociais, psicológicas, políticas, culturais, dentre outras. A distância se refere à disposição em determinada hierarquia. Por ser resultante de interação entre os sujeitos sociais localizados em pontos distintos da estrutura hierárquica, como, por exemplo, administrativa, cultural, econômica, espacial, política, religiosa, social, etc., trás, em si, a desigualdade como pressuposto. Ressalta-se que, como consequência das relações de oferta e de procura por parte dos indivíduos e/ou dos grupos, a distância não se efetiva somente através da diferenciação funcional, mas, fundamentalmente, por e a partir da desigualdade decorrente da hierarquização, onde há superiores e inferiores. Esses sistemas de tessituras, de nós e de redes organizadas hierarquicamente permitem assegurar 0 controle sobre aquilo que pode ser distribuído, alocado e/ou possuído. Permitem impor e manter uma ou várias ordens, além de assegurar a dominação de um determinado grupo sobre o espaço, formando, assim, os territórios. Desses e nesses sistemas se originam as relações de poder.

A acessibilidade, por sua vez, está direta e indiretamente relacionada à possibilidade de indivíduos e/ou grupos partilharem as mesmas áreas/locais. Como os territórios, através de suas barreiras físicas e/ou simbólicas (DAMATTA, 1985) são capazes de informar quem é de dentro e quem é de fora fica evidenciado que a sua demarcação é suficiente para indicar quais indivíduos e/ou grupos dele fazem parte. O acesso ou o não acesso é 
apresentado através da própria identidade que indivíduos e/ou grupos que se apropriaram do lugar impuseram a ele. Tem-se, então, que o território, independente de sua escala (micro ou macro) é portador da identidade de seus ocupantes, (GIDDENS, 1989), estando o acesso condicionado ao compartilhamento com os valores, as visões de mundo, interesses, etc. com os que nele atuam. Nesse sentido, Liberato (2007, p. 65) ainda acrescenta que:

A constituição de territórios se dá através da construção e a apropriação do espaço, sendo uma ação eminentemente política. Sendo assim, constituem-se prioritariamente em locais de identidade, de resistência, onde a história do local se confunde com a de seus habitantes. Conforma uma paisagem única na medida em que as configurações do local, a sua representação e, também, a sua imagem detêm traços que marcam a especificidade local que, por mais que possa, à primeira vista, ser parecida com outro, mantém a sua individualidade.

É através de suas especificidades que os espaços podem e devem ser analisados. Portanto, o território não é apenas um local onde se encontra recursos naturais e população, devendo ser compreendido a partir das suas características intrínsecas, prioritariamente pelos os processos de identidade que o formaliza, física ou simbolicamente. Também não podem ser negligenciadas as modificações sócio-espaciais através dos processos mutáveis de duração variada, pois a temporalidade é um elemento central na constituição dos territórios na medida em que esses podem ser efêmeros ou duradouros, transitórios ou definitivos dependendo da escala temporal que se emprega na análise. Fica evidenciado que as mudanças/alterações são bastantesfreqüentes dependendo da forma de apropriação e da quantidade de poder dos que apropriam detém. Assim, são possibilitadas configurações espaciais/territoriais diferentes.

Giddens (1989, p. 304) apud Liberato (2007, p.65) esclarece essa questão ao afirmar que "uma região física envolvida como parte do cenário de interação, tendo fronteiras definidas que ajudam a concentrar a ação num sentido ou noutro, não podendo ser entendida como sendo apenas um ponto no espaço, pois se constitui tópos privilegiado. Desse modo, o local é, fundamentalmente, um território."

A noção de território tem como premissa que o espaço é multifacetado, fragmentado, com inúmeras possibilidades de recortes, de uso, de significados e de configurações distintas, podendo essas ser, até mesmo, contraditórias. O espaço (...) enquanto fenômeno de análise recobre-se de significados e significantes. Dialeticamente pode-se afirmar que o mesmo é construtor e construção de indivíduos que são por ele condicionados ao mesmo tempo em que, através de suas intervenções, o condicionam. Dessa forma, tem-se que a cada espaço há correspondentes modos de vida, concepções de mundo e de relações sociais, todos esses reflexos e refletores de atividades e atitudes dos indivíduos que por ele transitam. Enfim, mais que um "lugar" qualquer, o espaço, enquanto permeado de significados e significantes, se configura, antes de qualquer coisa, em um território. (LIBERATO, 2000. p. 33)

Portanto, o território deve ser analisado a partir das suas delimitações e composição cultural, social, política, econômica, étnica e efetivamente a partir das suas relações de poder, pois "O território é essencialmente um instrumento de exercício de poder: quem domina ou influencia quem nesse espaço, e como?"(SOUZA,1995, p.79)

Nessa perspectiva, Liberato (2007) ainda complementa que

o conceito de território, assim compreendido,
aponta para uma direção que nos parece mais
segura, pois indica, não somente, que este
detém limites que demarcam - possibilitando
ou impossibilitando - relações entre os de
dentro (insiders) e os de fora (outsiders),
como, também, encerra uma materialidade
que permite a identificação cultural dos grupos
sociais e os limites de atuação desses."
(2007, p. 68-69) Haesbaert (1995) usa o termo desterritorialização para tratar a dimensão espacial da sociedade capitalista em que vivemos, onde a desterritorialização seria a tentativa da superação de distâncias e limites impostos por "obstáculos geográficos" o que esse autor denomina como "entraves espaciais", isto posto, segundo Haesbaert (1995, p. 168), "trata-se de uma definição que 
relaciona a uma visão parcial do que se entende por território.". Em seguida discorre sobre o território e suas especificidades. Para o autor, a desterritorialização não se restringe apenas e tão somente ao desenraizamento decorrente do fim das fronteiras, pois

Se tomarmos a abordagem que eu denominaria de "funcional estratégica" de território, temos este como um espaço sobre o qual se exerce um domínio político e, como tal, um controle de acesso. Entretanto, se ampliarmos, essa definição, incorporando à dominação política uma apropriação simbólico-cultural, veremos que a desterritorialização não deve ser vista apenas como desenraizamento no sentido de uma destruição física de fronteiras e um aumento da mobilidade em um sentido concreto. (HAESBAERT, 1995. p. 168)

$\mathrm{Na}$ visão de Lefèbvre e Harvey a territorialização deve compreender a distinção entre domínio e apropriação do espaço. Segundo Harvey (1992, p.202) apudHaesbaert (1995, p.169) "o domínio do espaço reflete o modo como indivíduos ou grupos poderosos dominam a organização e a produção do espaço mediante recursos legais ou extralegais. A fim de exercer um maior grau de controle".

o espaço dominado é geralmente fechado, esterilizado, esvaziado. Seu conceito não adquire seu sentido a não ser por oposição ao conceito inseparável de apropriação. Sobre um espaço natural modificado para servir às necessidades e às possibilidades de um grupo, pode-se dizer que este grupo se apropria (...). Relacionada ao espaço de vivência cotidiana, a apropriação não pode ser compreendida sem o tempo, os ritmos de vida. (LEFÈBVRE 1986, p. 191 - 193 apudHAESBARERT,1995, p. 169)

Portanto, de acordo com Haesbaert (1995), quando nos referimos a desterritorialização devemos ter clareza das suas duas dimensões. A primeira política, mais concreta, e a segunda cultural, de caráter mais simbólico. Deve estar claro a dimensão de cada uma no papel de formação dos territórios. De acordo com o autor: "Embora fronteiras de domínio político possam corroborar e mesmo criar uma identidade cultural, como foi o caso de muitos Estados-Nações, nem toda fronteira de apropriação territorial no sentido cultural coincide com e/ou proporciona uma fronteira política concreta.(HAESBARERT 1995, p. 169)

A produção do espaço envolve a mesmo tempo territorialização e desterritorialização. Nesse sentido Barel (1986, p.139) apud Haesbaert (1995, p. 170) afirma que:

“(..) seria interessante se representar a mudança social (e seu contrário, o bloqueio) sob uma forma de uma dinâmica territorial, pois a mudança social é em parte esta: a vida e morte dos territórios. A mudança social é vista aqui como um movimento de territorialização - desterritorialização reterritorialização (...)".

Para ficar clara a concepção de território e rede, Haesbaert, através das concepções de Levy, Guattari, Baudrillard, Berque e Augé, correlacionou a territorialização e a desterritorialização e classificou utilizando as seguintes variáveis: dimensões sociais fundamentais, dimensões de elementos espaciais, noções correlatas, tendências gerais e dilemas principais

Considerando as dimensões sociais, a territorialização ocorre a partir das dimensões política e cultural, já a desterritorialização se concretiza com interferências econômicas e políticas. Em relação aos elementos espaciais a territorialização é horizontalmente formada, de acordo com a área/superfície e o limite/fronteira, formando efetivamente o território. Já a desterritorialização é formada verticalmente, através de pontos e linhas, polos e fluxos, limiar/hierarquia, o que caracteriza uma rede. A territorialização pode ser correlacionada com o espaço físico concreto e a paisagem, porém a desterritorialização esta ligada diretamente com o meio, o não-lugar.

Desse modo, têm-se então as características gerais que distinguem claramente e forma a oposição dos processos de territorialização e desterritorialização. Enquanto a primeira qualifica, distingue e identifica (diferença e alteridade) gerando raízes de identidade, enraizamento e controle, a segunda, no entanto, quantifica, homogeneíza, gera desigualdade, distinção e mobilidade. Em suma, de 
acordo com Haesbaert, a territorialização esta ligada diretamente a segregação sócio espacial, ou seja, o fechamento e o conservadorismo. Para esse autor, no processo de desterritorialização gera exploração, desintegração e instabilidade. (HASBAERT, 1995, p.177).

\section{A fronteira, o limite e a divisa no sistema territorial}

A idéia de limite é de suma importância na análise do sistema territorial. Colocar limite, estabelecer fronteiras, portanto, delimitar é ponto central nos estudos sobre território. Ao colocar limite, definir fronteiras e delimitar áreas os homens isolam ou subtraem, temporária ou perenemente, parte do espaço, ou seja, estabelecem um território.

Nesse sentido, faz-se necessário considerar que os limites não devem ser concebidos apenas do ponto de vista linear, mas também do ponto de vista zonal. As tessituras de origem política, aquelas criadas pelo Estado, em geral têm uma permanência maior do que as resultantes de uma ação dos outros atores, pois os limites políticos e administrativos, definidos pelo poder público (Nações, Estados, Municípios), são bem mais estáveis, enquanto os limites econômicos 0 são bem menos, pois apresentam muita dinamicidade. (RAFFESTIN, 1980, p. 155). O território deve ser analisado tendo por base que ele é, ao mesmo tempo, produto e produtor de territorialidades.

Nessa perspectiva, a territorialidade adquire um valor bem particular, pois reflete a multidimensionalidade do "vivido" territorial pelos membros de uma coletividade. Os homens vivem, ao mesmo tempo, o processo territorial e o produto territorial por intermédio de um sistema de relações existenciais. A identificação da noção de territorialidade coloca problemas. $\mathrm{Na}$ tradição americana a territorialidade é definida como: "Um fenômeno de comportamento associado à organização do espaço em esferas de influência ou em territórios nitidamente diferenciados, considerados distintos e exclusivos, ao menos parcialmente, por seus ocupantes ou pelos que os definem." (SOJA, p. 19). De acordo com Liberato (2007, p.81-82)

Os territórios, enquanto locais dotados de significados, são definidos e delimitados por e a partir de relações de poder. Podem ser construídos e/ou desconstruídos a partir de escalas geográficas e temporais diversas e ter caráter permanente ou transitório. $\mathrm{E}$ mais, os territórios, ao contrário do espaço global, da região e do lugar, expressam e, ao mesmo tempo, são expressões inequívocas da espacialidade presente nas mais variadas conformações sociais.

Os termos fronteira e limite de acordo com a literatura pesquisada carecem de precisão teóricoconceitual, pois são amplamente utilizados, tanto no nível do senso comum, quanto na academia, em especial nas áreas de Geografia, Geopolítica, História, Sociologia, Antropologia, dentre outras, como sinônimos. Todavia, esses apresentam diferenças que requerem uma análise mais detida buscando identificá-las.

De acordo com Martin (1992), os limites podem ser alterados sem grandes transtornos, desde que dois Estados, (municípios ou províncias, etc.), tenham disposição política em fazê-lo, bastando para isso o concurso de técnicos competentes: topógrafos, geógrafos e juristas. No entanto, mesmo no Direito Público, apesar da costumeira demarcação da linha divisória, pretende-se que, para maior tranquilidade da população fronteiriça, seja preferível sempre se reconhecer uma faixa de certa largura.

Ainda segundo Martin (1992), o limite aparece como uma linha puramente imaginária, marcada na superfície terrestre por objetos naturais ou artificiais. De acordo com esse autor, é possível tentar acrescentar outro elemento ao mesmo tempo distinto tanto do limite, quanto da fronteira: trata-se da divisa, o aspecto visível do limite. Sendo assim, o marco, a baliza, aparecerão como pontos fixos, erguidos pelo homem, os quais, alinhavados expressam o limite de jurisdição dos Estados (Municípios, províncias, etc.). Boa parte da literatura técnica a respeito dedica-se a discutir qual o melhor apoio físico para os limites. Desse modo, se torna relevante diferenciar demarcação da delimitação. 
Conforme aponta Guimarães, citado por Martin (1992)

(...) a polêmica das fronteiras decorre de uma identificação apressada entre duas práticas na verdade distintas. Uma está ligada a problemas de teoria e tem chamado a atenção em especial dos geógrafos, como também dos economistas, cientistas políticos e homens do Estado: trata-se da delimitação. A outra se dedica à resolução de problemas de ordem técnica, a ela estão vinculados os topógrafos, cartógrafos, geodesistas e até astrônomos: a demarcação.

Em suma, delimitação se estende pelo estabelecimento de uma linha de fronteira. Já a demarcação é a locação de uma linha de fronteira no terreno, a construção da divisa se dá a partir do estabelecimento de marcos e balizas. De acordo com o autor, a demarcação deve subordinar-se à delimitação. Todavia, não é isso que ocorre, mais ao contrário, a delimitação que acaba cedendo às facilidades da demarcação.

Segundo MOODIE (1992) "a fronteira se distingue do limite precisamente porque o primeiro é natural e remete, portanto, à Geografia, enquanto o segundo é artificial e remete diretamente ao Estado". Já Foucher ${ }^{1}$, citado por Magnoli e Araújo (s.d), esclarece que:

As fronteiras, enquanto estruturas espaciais elementares exercem funções de descontinuidade geopolítica, de delimitação e demarcação em três níveis: real, simbólico e imaginário. O real representa o limite espacial de exercício de uma soberania (...). O simbólico remete à participação em uma comunidade política inscrita num território que Ihe pertence: é um sinal identitário. O imaginário conota as relações com o outro, vizinho, amigo ou inimigo e, portanto, as relações da comunidade com a sua história e seus mitos fundadores (...). A fronteira não é, então, um limite funcional banal, com simples funções jurídicas ou fiscais. (Grifos nossos)

Enquanto uma estrutura espacial imaterial, as fronteiras não podem ser captadas pelos meios amplamente utilizados na atualidade como, por exemplo, fotografias aéreas ou imagens de satélite.

\footnotetext{
${ }^{1}$ Foucher, Michel (1991) Fronts etfrontières. Un tour du monde géopolitique. Paris, Fayard, 2e édition, p. 691.
}

Mas isso não quer dizer que esses meios não possam ser empregados na análise sobre a produção e a apropriação do espaço pelo homem. Nessa perspectiva o conceito de fronteira ultrapassa o de limite e, devido a sua relevância, requer que sua análise ultrapasse as suas funções jurídicas ou fiscais na medida em que está diretamente ligado à esfera da cultura.

Não pode ser desconsiderado que a fronteira é um marco e que sua delimitação não é impeditiva da interação dos atores sociais, pois em sua área há povoações. Já o limite, por ser um fator de separação, pois aparta as unidades territoriais, em suas diversas escalas (internacionais, nacionais, municipais, locais, grupais) normalmente se constitui como um obstáculo fixo, não importando a presença de fatores comuns, físico-geográficos, sociais, econômicos, políticos ou culturais. Assim, o limite é reconhecido como linha e, por esse motivo, não pode ser habitado. Deve ser salientado como o faz Martin (1992) que este, na maioria das vezes, é definido/demarcado por cursos d'água, linhas de trem, rodovias, cristas montanhosas, coordenadas geográficas ou outras linhas geodésicas. Porém, Liberato (2007, p. 66) ressalta que:

É importante salientar que as fronteiras dos territórios são em sua grande maioria simbólicas e que a demarcação dessas, ou seja, a fixação dos limites territoriais, é decorrente das lutas incessantes entre os vários grupos para ocupar cada vez mais espaço, seja esse último físico e/ou simbólico.

Não pode ser ignorado que o termo limite designa o fim de uma determinada unidade políticoterritorial e que toda propriedade ou apropriação é marcada por limites visíveis ou não, assinalados no próprio território. Nesse caso, os limites mantém estreita ligação com o exercício do poder. O limite cristalizado se torna ideológico, pois de acordo com Raffestin (1980) justifica territorialmente as relações de poder.

Ainda segundo Raffestin (1980, p. 19),

(...) o limite é, portanto, uma classe geral, um conjunto cuja fronteira é um subconjunto. Ainda aí é particularmente estranho que só a 
fronteira tenha uma conotação política enquanto, de fato, todo limite possui uma, nem que seja só pelo fato de ele ser sempre a expressão de uma manifestação coletiva, direta ou indireta. A fronteira é manipulada como instrumento para comunicar uma ideologia.

Outro conceito distinto tanto do de limite quanto do de fronteira é o de divisa ou marco de fronteira. Esse, por sua vez, se constitui no aspecto visível do limite, pois é um ou mais pontos fixados pelo homem em uma determinada área, sendo, portanto, um símbolo visível do limite.

\section{Considerações finais}

Diante do exposto, ficou claro que a Geografia Política oferece uma ampla possibilidade de conexão escalar para efetivação de estudos que envolvem as relações de poder, especificamente emergindo a temática dos territórios, e/ou disputa por estes. O território, portanto, como categoria de análise geográfica, é o lócus, onde se concretiza essas relações sociais e objeto de suma importância na efetivação de estudos destinados a tratar da Geografia Política. A polêmica das fronteiras é um resultado da expansão capitalista e, tal como já explicitado, uma crescente "desterritorialização", ou mundialização dos territórios através de fluxos contínuos, marcada pelo não lugar.

\section{Referências}

BECKER, Bertha K. A Geopolítica da virada do milênio: logística e desenvolvimento. In. CASTRO, Iná Elias. GOMES, Paulo C. da Costa. CORREAA, Roberto Lobato. Geografia: conceitos e temas. Rio de Janeiro: Bertrand Brasil, 1995. P.271-307.

CASTRO, Iná Elias. GOMES, Paulo C. da Costa. CORREAA, Roberto Lobato. Geografia: conceitos e temas. Rio de Janeiro: Bertrand Brasil, 1995.

CLARK, David. Introdução à geografia Urbana. 2 ed. (Trad. Lúcia Helena de Oliveira Gerardi e Silvana Maria Pintaudi, Coord. Editorial de AntonioChristofoletti). Rio de Janeiro: Bertrand Brasil, 1991.

CLAVAL, Paul. Os quadros conceituais da análise das situações de conflitos em Geografia Política. L' Espace Geographique, Paris: Doin, 1987, p. 269 276.
DAMATTA, Roberto. Espaço: Casa, rua e outro mundo: o caso do Brasil. In. DAMATTA, Roberto, $A$ casa e a rua: espaço, cidadania, mulher e morte no Brasil. São Paulo, Brasiliense, 1985. p. 25-54.

FOUCAULT, Michel. Microfísica do poder. Rio de Janeiro: Graal, 1979.

GIDDENS, Anthony. Tempo, espaço e dominação. IN GIDDENS, Anthony. A constituição da sociedade. São Paulo: Martins Fontes, 1989. p. $89-131$.

HAESBAERT, Rogério. Desterritorialização: entre as redes e os aglomerados de exclusão In.CASTRO, Iná Elias. GOMES, Paulo C. da Costa. CORRÊA, Roberto Lobato. Geografia: conceitos e temas. Rio de Janeiro: Bertrand Brasil, 1995. P.165-205.

HAESBAERT, Rogério. O mito da desterritorialização: do "fim dos territórios" à multiterritorialidade. Rio de Janeiro: Bertrand Brasil, 2004.

HAESBAERT, Rogério. Regional - Global: dilemas da região e da regionalização na geografia contemporânea. Rio de Janeiro: Bertrand Brasil, 2010.

HORTA, Célio. Geografia Política e Geopolítica: Velhas e Novas Convergências. Geografia. Ano VIII. n 15, 2006. p. 51-69.

LACOSTE, Yves. A geografia - isso serve, em primeiro lugar, para fazer a guerra. (Trad. Maria Cecília França). Campinas: Papirus, 1988.

LIBERATO, Rita de Cássia. Cidade e exclusão. O lugar de moradia dos excluídos: O caso de Belo Horizonte. (Tese de Doutorado em Geografia: Tratamento da Informação Espacial) Belo Horizonte: PUC Minas, 2007.

MAGNOLI, Demétrio e ARAÚJO Regina. Projeto de ensino de geografia. In. http://www.moderna.com.br/moderna/didaticos/em/ge ografia/projensinogeo/rumos/0013.Acessado em $18 / 10 / 2007$.

MARTIN, André Roberto. Fronteiras e Nações, São Paulo; Contexto, 1992.

RAFFESTIN,C. Por uma geografia do poder, São Paulo, Ática, 1980.

SOJA, Edward W. Geografias pós-modernas: a reafirmação do espaço na teoria social crítica. (Trad. Vera Ribeiro). Rio de Janeiro: Jorge Zahar Editores, 1993.

SOUZA, Marcelo. O Território: sobre espaço e poder, autonomia e desenvolvimento.In. CASTRO, Iná Elias. GOMES, Paulo C. da Costa. CORRÊA, Roberto Lobato. Geografia: conceitos e temas. Rio de Janeiro: Bertrand Brasil, 1995. P.77-111. 